\title{
MULHERES BRASILEIRAS EM PORTUGAL E VIOLÊNCIA DE GÊNERO: DESAFIOS MIGRATÓRIOS EM CONTEXTO INTERNACIONAL
}

\author{
Marly de Jesus Sá DIAS \\ Universidade Federal do Maranhão/CEMRI-UAb. \\ marlydejesus@yahoo.com.br \\ Maria Natália RAMOS \\ Universidade Aberta de Lisboa/ CEMRI. \\ natalia@uab.pt
}

\begin{abstract}
Resumo
O presente texto discute o fenómeno da migração em Portugal, país atualmente eleito por brasileiras/os como residência por motivações diversas, com destaque na progressão numérica de mulheres desta nacionalidade. Parte-se da premissa de que o processo de integração num novo território depende de numerosas condições e superação de desafios que, possivelmente, se elevam para as mulheres e que as podem expor a situações violentas e difíceis. Pesquisas revelam que a violência contra as mulheres é recorrente em todo o mundo e em diferentes espaços da vida social, com perdas e danos para as mulheres, famílias e sociedade, dadas as suas vulnerabilidades sociais, económicas e culturais. Subsidiada por revisão bibliográfica e documental, esta reflexão procurou apreender se o fenómeno da migração, na sua relação com o género, concorre para a violência de género que atinge brasileiras nesta condição em Portugal. Conclui-se que a condição de imigrante não pode ser, por si só, responsabilizada por situações de violações aos direitos humanos e exclusão social. Contudo, essa condição, em circunstâncias nas quais se inclui o recorte género, geração, etnia, classe orientação sexual, pode contribuir para a violência de género, que faz das mulheres vítimas frequentes, motivo pelo qual urge fortalecer e ampliar as políticas públicas e a luta em prol do reconhecimento destas mulheres como sujeitos de direitos e na perspetiva de construção de uma sociedade mais justa e equitativa entre os seres humanos.
\end{abstract}

Palavras-chave: migração internacional; violência de género; mulheres migrantes; brasileiras em Portugal.

\begin{abstract}
The present text discusses the phenomenon of migration in Portugal, a country currently chosen by Brazilians as a residence for various motivations, with emphasis on the numerical progression of women of this nationality. It starts from the premise that the process of integration into a new territory depends on numerous conditions and the overcoming of challenges that possibly arise for women and can expose them to violent and difficult situations. Research reveals that violence against women is recurring across the world and in different spaces of social life, with losses and damages for women, families and society, given their social, economic and cultural vulnerabilities. Supported by bibliographical and documentary revision, the reflection sought to understand if the phenomenon of migration, in its relation with the gender, contributes to the gender violence that reaches Brazilians in this condition in Portugal. It is concluded that the status of immigrant can not be held accountable for situations of human rights violations and social exclusion. However, this condition, in circumstances in which gender, generation, ethnicity, and sexual orientation may be included, may contribute to gender-based violence that makes women frequent victims. This is why it is necessary to strengthen and expand public policies and the struggle for recognition as subjects of rights and in the perspective of building a more just and equitable society among human beings.
\end{abstract}

Keywords: international migration; gender violence; migrant women; Brazilian women in Portugal. 


\section{Introdução}

A migração é um fenómeno social antigo, motivado por fatores diversos e que na contemporaneidade adquire novos contornos e complexidades, dada a sua recorrência, temporalidade, progressão numérica, diversificação dos fluxos, perfis, destinos e impactos nos países de saída e de chegada (demográfico, social, económico, político, cultural). No seio dessas mutações e evoluções migratórias, diferenças de género fazem-se presentes em termos quantitativos e qualitativos. O número de mulheres imigrantes aumenta relativamente ao de homens nesta condição no mundo inteiro, o que confere visibilidade e importância relativas ao público feminino no conjunto da população estrangeira, inclusive enquanto sujeito ativo do processo migratório, originando o que a literatura tem denominado de feminização das migrações (RAMOS, 2011, 2014; RAMOs, MC, 2013, 2015; MARQUES \& GÓIs, 2012; OLIVEIRA \& GOMES, 2017).

Dados do Observatório das Migrações, divulgados no Relatório "Indicadores de Integração de Imigrantes", informam que, no universo de migrantes internacionais, é cada vez maior o número de países em que a proporção de mulheres ultrapassa a dos homens, a exemplo de Portugal, com uma realidade migratória marcada por algumas oscilações, ocupando, em janeiro de 2016, o 21. lugar entre os 28 países do espaço europeu em número de estrangeiros residentes $(3,8 \%)$ e cuja população migrante estrangeira está concentrada, principalmente, em Lisboa, Porto e Faro (RAMOS, 2015; OLIVEIRA \& GOMES, 2017).

Desde a década de 1980 que Portugal se evidencia como país de imigração, acolhendo pessoas originárias de países diversos, além daqueles com quem mantém laços históricos, coloniais, culturais, políticos ou económicos, com destaque para os PALOP e para a presença crescente de mulheres.

O Serviço de Estrangeiros e Fronteiras (SEF), citado pelo já referido Relatório, menciona que a tendência da feminização vem sendo observada no país desde 2012, com as mulheres estrangeiras a registar uma progressão contínua nas duas últimas décadas (em 2011, representavam menos 0,3 pontos percentuais que os homens, passando para mais 2,9 pontos percentuais em 2015 e mais 3 pontos percentuais em 2016) (OLIVEIRA \& GOMES, 2017: 55). Informação similar foi evidenciada também por Marques e Góis (2012), que registam que entre 1999 e 2008 este crescimento foi de $158 \%$, contra um aumento masculino de $110 \%$, com destaque para as mulheres que migram por decisão própria e autónoma. No ranking das 10 nacionalidades em que as mulheres estão numericamente mais representadas em Portugal ${ }^{1}$, o Brasil ocupava, em 2016, posição de destaque, liderando com $61,9 \%$ no total de residentes dessa nacionalidade (OLIVEIRA \& GOMEs, 2017).

Convém lembrar que a migração é bem mais do que um simples deslocamento ou percurso de saída e de chegada num novo destino, imprimindo vários desafios, o que fomentou inquietações expressas nesta reflexão, cujo objetivo é analisar se o fenómeno da imigração em contexto

\footnotetext{
${ }^{1}$ Os 10 países referenciados pelo Relatório Indicadores de Integração de Imigrantes, segundo a distribuição por sexo das principais nacionalidades residentes em Portugal em 2016, são: Brasil, Angola, Cabo Verde, Ucrânia, China, Espanha, Reino Unido, França, Guiné-Bissau e Roménia. Mais detalhes em OLIVEIRA e GOMES (2017: $57)$.
} 
internacional, na sua relação com o género, concorre para a violência de género em mulheres brasileiras nesta condição em Portugal. Trata-se de um estudo qualitativo, exploratório e descritivo, subsidiado pela revisão bibliográfica e documental, no qual se parte da permissa de que o processo de integração num novo espaço geográfico depende de uma série de condições legais, ambientais, habitacionais, económicas, emocionais, psicológicas (RAMOS, 2004, 2008), que possivelmente aumentam para as mulheres que emigram sem quaisquer redes de relações sociais no país de destino, por vezes indocumentadas, ao mesmo tempo que as pode expor a situações violentas, expressas através de discriminações étnicas, sexistas, geracionais, materializadoras da dominação e opressão de género que atinge também as mulheres e que pode interseccionar-se com outras pertenças, como a classe social, a nacionalidade e o estatuto migratório (RAMOS \& FRANKEN, 2018; QUEIROZ, 2018).

Por outro lado, alguns dados revelam que vários tipos de violência contra as mulheres têm sido recorrentes em todo o mundo e em diferentes espaços, seja em casa (violência doméstica, familiar), seja fora desta, a exemplo do mundo do trabalho (RAMOS MC \& PATRICIO, 2015). Estas diferentes violências permeiam todas as esferas da vida social em diferentes sociedades e contextos, independente da classe, etnia, idade, religião, orientação sexual, identidade de género ou estatuto civil das vítimas, apresentando-se como uma realidade concreta, problema universal expresso de forma diferenciada e com distintas implicações, com perdas e danos para as mulheres, de modo geral, famílias e sociedade, dadas as suas vulnerabilidades sociais, económicas, culturais, cuja análise precisa ser feita compreendendo a singularidade e subjetividade de cada situação e de cada mulher.

\section{Feminização das migrações: protagonismos e desafios para mulheres}

O fenómeno migratório é complexo, global e multidimensional (RAMOS, 2008, 2014, 2018), e, no caso Brasil/Portugal, igualmente recente, o que faz com que os seus efeitos sejam diversos e de extensões desconhecidas. Como já referido, os brasileiros figuram em Portugal como principal comunidade imigrante, com maior número de residentes, totalizando 81.251 cidadãos e cidadãs em 2016, de acordo com dados do SEF (2016).

Se, tradicionalmente, a história da imigração portuguesa era marcada pela prevalência do sexo masculino, a partir da década de 2000 a percentagem de mulheres aumenta, com algumas flutuações em 2006 e 2007, por exemplo, facto observado na comunidade brasileira e em todos os grupos nacionais residentes neste território, ainda que a maior percentagem de homens permanecesse na população total (MARQUES \& GÓIS, 2012). Vale a pena ressaltar que a adoção da categoria sexual ou de género nos estudos dessa natureza se apresenta como uma das hipóteses explicativas para a atual percepção da progressão e participação ativa da população feminina nos processos migratórios em geral, referenciada como feminização das migrações.

Conforme Marques e Góis (2012), até à década de 1980 a migração das mulheres era analisada apenas como decorrente da migração masculina, possivelmente por ser a mais frequente, 
o que as colocava na condição de "seguidoras passivas" dos seus familiares homens. As estatísticas não se apresentavam especificadas em função do critério sexo, o que, por certo, contribuiu para insuficiências e dificuldades na compreensão da sua importância nos fluxos migratórios, do qual sempre fez parte, embora com diferentes percentagens.

Os estudos de género configuram-se como fundamentais, "tanto para a observação dos fluxos migratórios no seu conjunto, como enquanto variável explicativa para diferenças significativas entre fluxos migratórios de diferentes nacionalidades" (MARQUES \& GÓIS, 2012: 23), e, principalmente, para dar visibilidade aos protagonismos das mulheres nesse processo, a exemplo das motivações que as fazem emigrar, dos meios e formas de inserção económica, das dificuldades enfrentadas para adaptação a esta realidade social, bem como para mostrar as suas particularidades enquanto categoria plural, uma vez que as mulheres não são todas iguais, provindo de vários lugares, estratos sociais, etnias, e possuindo diversos valores culturais e sociais, idades, escolaridades, ocupações laborais.

A intersecção do género com outras divisões sociais que têm como base a
nacionalidade, os níveis de educação, os recursos económicos, sociais e/ou
culturais em conjunto com as políticas migratórias ou de integração cria uma
complexa (e quase sempre invisível) matriz de estratificação que importa desocultar
(MARQUES \& GÓIS, 2012: $24-5$ ).

Essa visibilidade é fundamental para que essas outras dimensões da vida social possam ser consideradas, uma vez que as relações de género permeiam todas as esferas da produção e reprodução da vida em sociedade, extrapolam a dualidade homem/mulher e remetem para relações assimétricas de poder entre ambos, estabelecendo uma divisão e hierarquia em que as categorias género-classe-raça/etnia-geração e nacionalidade se entrelaçam. Ou seja, conformam lugares, papéis e significação destas relações de poder de forma desigual na vida das pessoas de ambos os sexos. Segundo Mira (2017: 26), "O género vai-se construindo, classificando os corpos com marcas visíveis e invisíveis - através de gestos, posturas, vestuários, reforçando lugares e expectativas sociais". Logo, ao acrescentar a categoria género nestes estudos sobre a migração, ampliam-se as possibilidades de intepretação do real, de perceção de que as mulheres historicamente têm desempenhado um papel importante nos vários domínios da vida, inclusive nos fluxos migratórios. Torna-se igualmente imperativo para a formulação e implementação de políticas públicas com a transversalidade de género, com vista a garantir e a resguardar direitos sociais, económicos e políticos basilares para que se possam integrar e participar no país de destino, distante e diferente daquele em que viviam.

As motivações para a eleição de Portugal como destino são diversas, no contexto dos fluxos migratórios. Muitos são os fatores de atratividade que certamente pesam nesta decisão, como, por exemplo: o seu desempenho no cenário internacional entre os países com melhores enquadramentos de cidadania (1. lugar); os bons resultados na aquisição da nacionalidade no total de residentes estrangeiros (3.․ lugar entre os países da Organização para a Cooperação e Desenvolvimento Económico-OCDE, em 2014); melhores resultados em relação aos demais países da União 
Europeia (UE) no que diz respeito a "atitudes pessoais face à discriminação" (OLIVEIRA \& GOMES, 2017).

Presume-se que, no caso específico das mulheres brasileiras, além dos atrativos pontuados, a eleição igualmente tenha em conta a familiaridade com a língua, os laços históricos e culturais entre os dois países, bem como a busca financeira, expressa na expectativa de trabalho (independente, temporário ou permanente), sobretudo no contexto da crise económica, política e ética que assola o Brasil nos últimos tempos, ao lado de motivações não económicas, igualmente significativas, tais como a facilidade para emigrar mediante os avanços legislativos na área da imigração ${ }^{2}$, o processo de entrada no espaço europeu menos burocratizado, a segurança, a educação com qualidade para aprimoramento dos estudos/profissões, a saúde pública com taxações moderadas e isenções destas em alguns casos, ou as ligações afetivas com alguém nascido e/ou residente em Portugal.

Contudo, nesse percurso migratório não faltam dificuldades e desafios para as mulheres, pois, embora esse processo seja constituído por uma multiplicidade de sujeitos (o ser que migra, o local de saída e de chegada, o processo de legalização), é uma experiência singular, vivenciada de forma particular, individual, com expectativas e desejos alimentados por essas pessoas que chegam, oriundas de todas as regiões do Brasil, com as suas crenças, valores, atitudes, comportamentos e na condição de imigrantes. A imigração é, assim, múltipla, complexa e heterogénea (RAMOS, 2015). Deste modo, a migração tanto pode ser uma experiência positiva e contribuir para o crescimento pessoal, como pode ser negativa, impulsionadora de tensões, angústias, sofrimentos, por ausência ou excesso de identificações (RAMOS, 2004, 2008, 2009, 2014; XAVIER, 2007) e múltiplas vulnerabilidades, "devido às rupturas, transformações e mudanças psicológicas, culturais, linguísticas, laborais, sociais, familiares, ambientais e políticas" (RAMos, 2015: 2956), por vezes agravadas por estereótipos e preconceitos negativos que geram discriminações, humilham, constrangem, caracterizadores de violências de género, manifestas em função do género a quem se destina a opressão, podendo ser mulheres ou homens.

\section{Violência de género em mulheres brasileiras imigrantes em Portugal}

A violência de género é entendida como fenómeno social e como uma das várias formas de expressão das desigualdades sociais entre homens e mulheres. É caracterizada por qualquer ato, omissão ou conduta (direta ou indireta) que provoque sofrimentos físicos, sexuais ou mentais, através de enganos, ameaças, intimidações, humilhações, que recusem a dignidade humana, a autonomia sexual, a integridade física e/ou moral de quem a sofre, que abalem a sua segurança pessoal, amor próprio, personalidade, ou ainda que afetem as suas capacidades físicas e intelectuais (CUNHA \& PINTO, 2008: 24).

\footnotetext{
${ }^{2}$ Segundo o quarto relatório que analisa e compara as políticas de integração de imigrantes em todos os países europeus e também na Austrália, Canadá, Islândia, Japão, Coreia do Sul, Noruega, Suíça, Turquia e Estados Unidos, contabilizando um total de 38 países, Portugal ocupa a segunda posição em termos globais relativamente às políticas favoráveis à integração dos imigrantes. Mais detalhes em: http://www.mipex.eu/portugal
} 
A violência de género perpetrada contra mulheres remonta às desigualdades de género e ao patriarcado, remodelada no e pelo capitalismo, contexto em que se alia à violência estrutural com acréscimos das opressões de etnia e de classe, conformando um sistema de dominação-exploração que Saffioti (2004) intitula de "patriarcado-capitalismo", responsável por injustiças sociais e desigualdades de várias ordens, como nas relações homem-mulher, entre etnias e classes sociais. Nas sociedades de classes, particularmente na sociedade capitalista, as diferenças biológicas entre os sexos masculino e feminino que demarcam possibilidades e impossibilidades de cada um (MIRA, 2017) foram convertidas em desigualdades históricas tidas como naturais quando foram socialmente construídas com distribuição desigual de poder, prestígio e oportunidades. E, qualquer que seja a sua modalidade (simbólica, física, sexual, psicológica, patrimonial), a discriminação, dominação e exploração sofridas pelas mulheres fazem-se latentes de formas diversas.

Secularmente, as mulheres, ao lado de outras categorias sociais, a exemplo de negros, índios, homossexuais, crianças, sofrem com as discriminações e violências, seja por parte de outrem, seja por parte do Estado. Convém lembrar que os problemas que atingem as mulheres na condição de imigrantes não estão à margem daqueles vigentes na sociedade patriarcal em que preconceitos e estereótipos são disseminados para reforçar modelos, padrões de comportamentos e manter as estruturas de poder instituídas, seja nos espaços públicos ou privados, seja instrumentalizando, anulando ou reduzindo a importância das mulheres no contexto social e político (KERGOAT, 1996; SAFFIOTI, 2004).

Mesmo figurando como importante objeto de vários tratados internacionais, entre os quais se destacam a Convenção de Eliminação de Todas as Formas de Discriminação contra a Mulher (1979), a Declaração da Eliminação da Violência contra a Mulher (1993), a Convenção Interamericana para Prevenir, Punir e Erradicar a Violência contra a Mulher (1994), a Plataforma de Ação de Beijing (1998), entre outros, que favoreceram avanços deste problema no âmbito do direito internacional, bem como para a adoção de legislações específicas com vista a assegurar os direitos da ala feminina, a persistência da discriminação é visível nas relações íntimas e familiares, no mundo do trabalho, com predomínio de diferenças salariais consoante o sexo dos profissionais, na parca representação feminina nas instâncias decisórias, nos sectores públicos ou privados, persistindo como um grave desrespeito aos direitos humanos.

Uma cultura de tolerância para com determinados atos que a caracterizam (humilhações, constrangimentos, ameaças, assédios) tem imperado para que esta herança patriarcal seja disseminada, naturalizada, banalizada, ou simplesmente ignorada, o que em muito contribui para que tais violações nem sempre cheguem, ou demorem a chegar, ao conhecimento das autoridades competentes, estando o medo, a vergonha e a dependência financeira dos parceiros entre as principais causas que conduzem à omissão e ao silenciamento.

Como já referido, muitas das mulheres que imigram atualmente para Portugal fazem-no por decisão própria, autónoma, como parte de um projeto independente, emancipador, pessoal ou profissional, fora do contexto do reagrupamento familiar, contribuindo para a dinamização económica local, seja na condição de trabalhadoras, seja como consumidoras (SANTOS, 2005; RAMOS, MC, 2013, 2015), dado confirmado pelo "Relatório Indicadores de Integração de Imigrantes", de 2017, que 
mostra que houve uma redução do número de mulheres estrangeiras titulares de Autorização de Residência (AR) para o reagrupamento familiar em menos de $73 \%$. Em contrapartida, o mesmo regista o aumento de AR para mulheres imigrantes para fins de investigação e atividades altamente qualificadas (taxa de variação de mais de 132\%), para trabalho independente (taxa de variação de mais de $287 \%$ ) e para estudantes de nível superior (mais de $36 \%$ ).

Apesar de crescente e contínua, a migração individual ainda não se constitui maioritária no conjunto das migrações, sendo porém um indicador de que também neste domínio da mobilidade transacional o estatuto e o papel das mulheres estão em mutação (POLICARPO \& COSTA, 2012).Tratam-se de mulheres provenientes de vários meios sociais, estados civis, principalmente divorciadas, separadas ou solteiras (POLICARPO \& COSTA, 2012), com diversas idades (apenas $7,5 \%$ dos estrangeiros residentes possuem mais de 65 anos), predomínio da ala jovem, e em que a nacionalidade brasileira novamente se destaca com a maior concentração de pessoas com idades entre os 20 e os 49 anos, faixa etária ativa, com 71\% (OLIVEIRA \& GOMES, 2017: 55-6). Deslocamse sozinhas, sem famílias, e, por vezes, sem redes sociais e de suporte, no país recetor, isentas dos apoios expressos no estatuto do reagrupamento familiar, suportes importantes cujas ausências elevam as suas dificuldades.

Para Ramos (2015), ao mesmo tempo que a feminização das migrações pode promover múltiplas oportunidades a nível identitário, social, educacional e económico, pode igualmente implicar inadaptações, conflitos, stresses vários, doenças, riscos e vulnerabilidades psicossociais. Informações contidas no "Relatório Indicadores de Integração de Imigrantes" de 2017 evidenciam que, em Portugal, é entre os estrangeiros residentes que se verificam os maiores riscos de pobreza, privação material, rendimentos baixos, piores condições de vida, comparativamente aos nacionais, tal como ocorre nos demais países europeus (OLIVEIRA \& GOMES, 2017:169).

Marques e Góis (2012) assinalam que muitas das mulheres migrantes, independentemente da nacionalidade, se inserem no mercado de trabalho dos países de acolhimento com dificuldades, em setores vinculados aos serviços de cuidados a idosos e domésticos, atividades profissionais muitas vezes aquém das suas habilitações, com requisições de baixas qualificações, sobretudo no âmbito do setor privado ou da economia informal, nichos femininos que reproduzem clivagens entre os sexos. Apesar de serem oportunidades encontradas para sobreviverem com rendimentos melhores que os auferidos no país de origem, são espaços laborais em que vigoram a informalidade na contratação, sem a devida regulamentação legal, e uma parca fiscalização, o que dificulta a reclamação de direitos, acesso aos mecanismos de proteção social, denúncias de casos de assédios, explorações com jornadas de trabalhos prolongadas e/ou sem pagamentos de horas extra, maus-tratos, entre outras situações que conformam violações em que as dimensões raça, etnia, classe social se entrecruzam com o género e, por vezes, com a nacionalidade (RAMOS, 2014; RAMOS, MC \& PATRICIO, 2015).

Marques e Góis (2012: 40-1) relatam que as migrantes com atuação nestes serviços pessoais e domésticos estão entre os grupos mais vulneráveis no mercado de trabalho. Policarpo e Costa confirmam e acrescentam que nesse processo migratório em que as mulheres se deslocam sozinhas, sejam casadas ou solteiras, esta vulnerabilidade é maior, tanto em relação aos homens imigrantes 
como às mulheres portuguesas, seja nas questões referentes ao trabalho, seja na vida íntima/privada. E, via de regra,

são sujeitas a uma dupla pressão: económica e relativa à vida privada. No primeiro caso, ganhar dinheiro, melhorar as condições de vida, inclusivamente enviar remessas para a família no país de origem. No segundo caso, manter a fidelidade matrimonial e uma "conduta sexual impecável", tendo muitas vezes que gerir o estigma por terem partido (e estarem fora da alçada do controlo da sociedade de origem, frequentemente muito sexista) (POLICARPO \& COSTA, 2012: 136).

A condição de mulher e imigrante concorre igualmente para uma maior exposição ao desemprego. Com base nos levantamentos feitos para a composição do livro intitulado $A$ Emergência das Migrações no Feminino, Marques e Góis mostram que o desemprego atinge 15,2\% das imigrantes e 4,7\% dos homens nesta condição; a remuneração média/hora é também desigual entre os sexos - o valor da remuneração média/hora para imigrantes é de 3,55€ para elas e 4,31€ para eles (MARQUES \& GÓIS, 2012: 47-9). A desigualdade de remuneração entre os sexos é real no mundo inteiro e demonstra o quanto o mercado laboral é estratificado, étnica e sexualmente, com desvantagem para o sexo feminino, bem como para negras e negros. Como destacam Policarpo e Costa (2011: 135), a realidade das mulheres imigrantes reflete a desigualdade de poder que caracteriza as relações de género em geral e também as relações no mercado de trabalho.

A partir de uma amostra com 1830 portugueses sobre as atitudes face à imigração e aos imigrantes em Portugal em 2010, tendo como referência três principais grupos de imigrantes (brasileiros, africanos e oriundos dos países da Europa do Leste), António (2011) mostra que os resultados expressam ambivalências reveladas pelos participantes do estudo, ora favoráveis à redução do número de imigrantes, ora com o reconhecimento de suas contribuições para a dinamização da economia e vida cultural local, com elevada apreciação pelos imigrantes dos países ocidentais (o Brasil ficou na terceira posição, juntamente com os asiáticos e europeus do leste). Revela ainda que "ser imigrante em Portugal não acarreta o mesmo tipo de experiências para uma pessoa originária de um país da União Europeia, de um dos Países Africanos de Língua Oficial Portuguesa (PALOP), do Brasil, da Ucrânia ou do Paquistão" (ANTÓNIO, 2011: 40). Neste sentido, grupos de imigrantes distintos cujas representações são partilhadas por um conjunto de indivíduos podem possuir diferentes graus de aceitação por parte da população portuguesa, muitas vezes sob a influência dos meios de comunicação em que a pertença de género e a origem geográfica dos e das imigrantes se fazem presentes. Dado o seu poder de influência, o que se dissemina a esse respeito, seja positivo ou negativo, interfere nos níveis de aceitação ou rejeição no que respeita aos e às imigrantes por parte da opinião pública.

Na sua dissertação de mestrado apresentada em 2007 e intitulada Redescobrindo o Brasil: processos identitários de brasileiros em Portugal, Mariana Xavier mostra como estereótipos socialmente construídos dificultam o respeito pela diversidade, ao mesmo tempo em que exacerbam outros estereótipos negativos que se reproduzem e se generalizam por desconhecimento, neste caso 
do Brasil e do seu povo, que não se resumem a futebol, samba, carnaval, mulatas e novela. A autora assinala igualmente, a partir de entrevistas realizadas com 17 brasileiros (nove do sexo feminino e oito do sexo masculino) oriundos de vários estados e regiões do país, a ambivalência destacada pelos participantes no modo como se consideram vistos por alguns portugueses. Por um lado, são descritos pelos nacionais como alegres, bem-dispostos, trabalhadores, e, por outro, se do sexo masculino, muitas vezes rotulados de marginais e de pouca cultura. Se do sexo feminino, são associadas à prostituição, à disponibilidade para programas sexuais em troca de dinheiro, oportunistas que migram em busca de casamentos com portugueses de posses. Queiroz (2018) acresce a essa reflexão a evidência de que as migrantes brasileiras tendem a ser racializadas em Portugal, percebidas como mestiças, hipersexualizadas, e, quando indocumentadas, experienciam situações em que as suas pertenças identitárias as expõem a vulnerabilidades como assédio moral e sexual.

A associação de estereótipos negativos como os que envolvem imigrantes brasileiras em Portugal interfere tanto no seu processo de integração na sociedade portuguesa como contribui para a redução de oportunidades diversas - habitacionais, laborais, comunicacionais, entre outras (MARQUES \& GÓIS, 2012: 57). É possível que a visão negativa que alguns nacionais têm da população imigrante brasileira tenha sofrido influência do caso de mulheres que, tempos atrás, na década de 1990, adentraram o território português pela rede do tráfico de mulheres para a exploração sexual e a prostituição e/ou do movimento promovido pelas mulheres de Bragança em 2003 contra a prostituição brasileira, bastante noticiado na imprensa portuguesa, ou ainda de situações que envolviam imigrantes brasileiros/as que extrapolam a civilidade e desrespeitam as normas locais por acharem que, estando longe de casa, podem fazer o que entenderem.

Cumpre esclarecer que, constitucionalmente (Artigo 15. da atual carta magna do país), estrangeiras/os residentes têm os mesmos direitos e obrigações dos cidadãos portugueses, exceto no que remete aos direitos políticos, exercício de funções públicas e redes de prostituição e tráfico humano que comportam várias nacionalidades. Assim como convém denunciar as discriminações sofridas por qualquer imigrante, independente do sexo ou da nacionalidade, fazendo-se urgente que as autoridades competentes coíbam generalizações que humilham, constrangem, adoecem, bem como a falta de respeito às regras e cultura locais pelos que chegam. Experiências negativas logo na chegada ajudam igualmente a reproduzir estereótipos e a minar relações (XAVIER, 2007).

Não se pode perder de vista que o acolhimento, a integração e o bem estar de quem é imigrante envolve um conjunto de elementos sociais, económicos, políticos, culturais, jurídicos, além da boa aceitabilidade local. Ou seja:

[...] aprender a viver, a comunicar e a trabalhar com o outro exige competências de cariz psicológico, social, cultural, pedagógico e comunicacional baseadas na experiência da alteridade e da diversidade e no equilíbrio entre o universal e o singular (RAMOS, 2015: 2958).

Deste modo, ainda que Portugal conte com um conjunto de legislação favorável à igualdade de direitos sociais entre os seres humanos, independente do sexo, etnia, idade, credo religioso, 
orientação sexual, e disponha de serviços públicos ou não governamentais com vista a contribuir para a integração dos imigrantes e defesa dos seus direitos, estes não se encontram materializados de forma concreta na vida de todas e de todos. Embora fundamentais, não têm conseguido enfrentar as relações patriarcais de género, seja pelo desconhecimento da sua existência por parte das vítimas, seja pela desatenção ao seu cumprimento.

\section{Considerações finais}

A migração internacional é uma realidade global, bem visível em Portugal. Nesse contexto, as mulheres apresentam-se com uma progressão contínua nos últimos anos no conjunto dos imigrantes das principais nacionalidades residentes no país. A comunidade brasileira destaca-se como aquela que apresenta maior evolução numérica de mulheres em relação aos homens, evidenciando protagonismos e desejos emancipatórios. Porém, ao mesmo tempo em que essa feminização de fluxos migratórios origina positividades, gera também inquietações.

A migração não é só diversa, complexa, portadora de oportunidades para as mulheres que emigram de forma independente, como parte de um projeto emancipatório, mas é igualmente permeada por dificuldades e desafios, agravados pelas questões de género, raça, classe, por vezes expressas em violências que historicamente têm atingido mais o público feminino, inclusive na condição de imigrantes.

Para as brasileiras que migram, sobretudo sozinhas, para Portugal, representações e estereótipos construídos socialmente pela população e que as associam a imagens negativas, principalmente ao mercado do sexo, constrangem, humilham, ao mesmo tempo em que abalam a sua integridade moral e psicológica. Sobretudo porque não refletem a realidade, dado que o trabalho que mais as absorve é a prestação de serviços domésticos e cuidados com doentes e idosos (Santos, 2005; Ramos, 2014). Estas representações e preconceitos reduzem as oportunidades de trabalho, lazer e arrendamento de habitação, ou seja, têm efeitos perversos que atingem a sua autoestima e os seus direitos. Embora tais estereótipos não correspondam ao pensamento da totalidade da população portuguesa, os danos que provocam são dolorosos.

É imperativo destacar que em Portugal vigora uma lógica não discriminatória e de acolhimento igualitário entre cidadãos nacionais e estrangeiros legalmente residentes, pelo que à partida não deveria comportar nenhum tipo de discriminação. Conforme Policarpo e Costa (2012), a grande maioria dos portugueses reconhece a importância que a contribuição dos imigrantes, principalmente das mulheres imigrantes, traz a esta nação. Contudo, estas discriminações subsistem de forma diversa e "atingem a mulher e impedem, de facto, o acesso a uma cidadania plena" (MARQUES \& GÓIS, 2012: 74). Nestes termos, ainda que a condição de imigrante não seja, por si só, causadora de violências de género, tal condição, em determinadas circunstâncias, nas quais se incluem os recortes de género, geração, etnia, classe, orientação sexual, nacionalidade, pode contribuir para tal violação, fazendo das mulheres vítimas frequentes.

Resta assinalar que a lógica não discriminatória e de acolhimento igualitário entre cidadãos nacionais e estrangeiros legalmente residentes, expressa num conjunto de políticas públicas vigentes 
em Portugal, precisa de ser mais divulgada entre a população imigrante, de modo a prevenir e punir algum tipo de discriminação e diferenciação em função de qualquer variável que estratifique as pessoas. O direito à igualdade de tratamento, à proteção, à migração, precisa ser universal. Afinal de contas, migrar é um direito humano.

\section{Bibliografia}

ANTÓNIO, João H. C.(2011). Atitudes face à imigração e aos imigrantes em Portugal. In ANTÓNIO, João H. C., POLICARPO, Vera. Os imigrantes e a imigração aos olhos dos portugueses: manifestações de preconceito e perspectivas sobre a inserção de imigrantes (pp.73-92). Lisboa: Fundação Calouste Gulbenkian.

EUROSTAT (2011). Indicators of immigrant integration: a pilot study, Eurostat Methodologies and Working Papers. Luxemburgo: European Commission.

KERGOAT, Daniele (1996). Relações sociais de sexo e divisão sexual do trabalho. In: LOPES, M. J. M.; MEYER, D.; WALDOW, V. (Orgs.) Gênero e saúde. Porto Alegre: Artes Médicas, pp. 55-61.

MARQUES, José Carlos \& GÓIS, Pedro (2012). A emergência das migrações no feminino: feminização das migrações de (e para) Portugal e suas consequências sociopolíticas. Lisboa: Fundação Calouste Gulbenkian.

MIRA, Rita (2017). O arquétipo da princesa na construção social da feminilidade. Lisboa: Edições Colibri.

ORGANIZAÇÃO MUNDIAL DA SAÚDE (2002). Relatório mundial sobre violência e saúde. Genebra: Ed. E. G. Krug, OMS.

POLICARPO, Verónica \& COSTA, Leonor Pereira da (2011). Imigração feminina: contacto e percepções de realidades diversas (pp. 133-166). In ANTÓNIO, João H. C \& POLICARPO, Vera. Os imigrantes e a imigração aos olhos dos portugueses: manifestações de preconceito e perspectivas sobre a inserção de imigrantes. Lisboa: Fundação Calouste Gulbenkian.

QUEIROZ, Camila Craveiro da Costa Campos (2018). Os estereótipos também envelhecem? Uma análise descolonial das intersecções entre racismo, sexismo e idadismo, a partir das vivências de migrantes brasileiras em Portugal. Dissertação de Mestrado. Braga: Universidade do Minho.

RAMOS, Maria da Conceição Pereira (2013). Globalização e multiculturalismo. Revista Eletrónica Inter-Legere "Políticas públicas, teorias e experiências", 13 (jul/dez), 75-101.

RAMOS, Maria da Conceição Pereira \& PATRícIO, Olívio (2015). Riscos laborais de homens e mulheres migrantes e segurança no trabalho (pp. 2948-2955). In Livro de Atas do 1.으. Congresso da Associação Internacional de Ciências Sociais e Humanas em Língua Portuguesa, 2015. Lisboa: Associação Internacional de Ciências Sociais e Humanas em Língua Portuguesa. Lisboa: CONLAB.

RAMOS, Natália (2004). Psicologia clínica e da saúde. Lisboa: Universidade Aberta.

RAMOS, Natália (2008). Saúde, migração e interculturalidade: perspectivas teóricas e prática. João Pessoa: Editora Universitária/UFPB.

RAMOS, Natália (2009). Saúde, Migração e Direitos Humanos. Mudanças - Psicologia da Saúde. 17 (1), 1-11.

RAMOS, Natália (2011). Gênero e migração: Dinâmicas e políticas sociais, familiares e de saúde (pp. 263-282). In Boschila, Roseli \& Andreazza, Maria Luísa. Portuguesas na diáspora. Histórias e sensibilidades. Curitiba: Editora UFPR.

RAMOS, Natália (2014). Migração, tráfico de pessoas e trabalho doméstico. Revista Políticas Públicas, 18 (2), 425-438. 
RAMOS, Natália (2015). Famílias migrantes nas cidades interculturais: acolhimento, solidariedade e saúde (pp 2956-2968). In Livro de Atas do 1. Congresso da Associação Internacional de Ciências Sociais e Humanas em Língua Portuguesa, 2015. Lisboa: CONLAB.

RAMOS, Natália \& FRANKEN, leda (2018). Cidadania e direitos aprisionados de brasileiros imigrantes ilegais na Suíça: Implicações na saúde e qualidade de vida. Revista Ambivalências. $6(11), 9-34$

SAFFIOTI, Heleieth I. B (2004). Gênero, patriarcado e violência. São Paulo: Fundação Perseu Abramo.

SANTOS, Clara Almeida (2007). Imagens de mulheres imigrantes na imprensa portuguesa: análise do ano 2003. Dissertação de Mestrado. Coimbra: Universidade de Coimbra.

SERVIÇO DE ESTRANGEIROS E FRONTEIRAS (2016). Relatório de Imigração. Fronteiras e Asilos. Lisboa: SEF.

UNITED NATIONS (2011). "Trends in international migrant stock: migrants by age and sex". [On line]. Disponível em: http:/www.un.org/esa/population/migration/CDROM\%20DOCUMENTATION UN MigrantStock 2010.pdf. [Acedido em: 30/05/2018]

XAVIER, Maria (2007). Redescobrindo o Brasil: processos identitários de brasileiros em Portugal. Dissertação de Mestrado. Lisboa: Instituto Superior do Trabalho e da Empresa.

ZLOTNIK, H. (1995). "The South to north migration of woman". In International Migration Review, Vol. XXIX (1), 229-454. 